\title{
Low Molecular Weight Chitosan from Shrimp Shell Waste using Steam-Explosion Process Under Catalyst of Phosphotungstic Acid
}

\author{
DINA SUGIYANTI',2, SRI ANGGRAHINI², YUDI PRANOTO², CHAIRIL ANWAR ${ }^{3}$ \\ and UMAR SANTOSO ${ }^{2 *}$
}

\begin{abstract}
'Nutrition Department, Faculty of Health and Psychology, Walisongo Islamic University, Jl. Prof Hamka Kampus II Ngaliyan, Semarang 50185, Indonesia.

${ }^{2}$ Department of Food and Agricultural Product Technology, Faculty of Agricultural Technology, Gadjah Mada University, JI. Flora, Bulaksumur, Yogyakarta 55281, Indonesia.

${ }^{3}$ Department of Chemistry, Faculty of Mathematics \& Natural Sciences, Gadjah Mada University, Yogyakarta, Indonesia.

*Corresponding Author E-mail: umars_santoso@yahoo.com
\end{abstract}

http://dx.doi.org/10.13005/ojc/350122

(Received: August 14, 2018; Accepted: December 01, 2018)

\begin{abstract}
The limited solubility of chitosan had limiting its application in any fields. Low molecular weight chitosan (LWCS) potentially produced to improve its solubility and characteristics. Steam explosion process was used to breakdown the intermolecular hydrogen bonding and phosphotungstic acid used as catalyst to attact the glycosidic bond and produce shorter chain. The optimum temperature, pressure and phosphotungstic acid concentration on steam explosion process presented highest water solubility at $\mathrm{T}=160^{\circ} \mathrm{C}, \mathrm{P}=6$ bar and $0.1 \%$, respectively. It didn't showed any change of functional group on FTIR analysis, no morphological damage by SEM analysis, and reduced the crystallinity. The particle size and molecular weight was reduced from $100 \mu \mathrm{m}$ to $255 \mathrm{~nm}$ and $5570 \mathrm{kDa}$ to $480^{\circ} \mathrm{Da}$, respectively. It can be known that LWCS potentially produced with high solubility and fine characteristics through steam explosion process catalyzed by phosphotungstic acid.
\end{abstract}

Keywords: Chitosan, Low molecular weight chitosan, Phosphotungstic acid, Steam explosion process.

\section{INTRODUCTION}

Chitosan is a natural biopolymer, derived from deacetylation of chitin, a major component of crustacean group shells such as crabs, shrimp and crayfish. Since the beginning of the $20^{\text {th }}$ century chitosan has been widely studied. Interest in chitosan is very high because chitosan is a biopolymer from a very abundant source in nature, so it was natural and easy to obtain, the required process cost is relatively $\operatorname{low}^{1,2}$. Currently chitosan was developed its applications to commercial, especially in the field of biomedical, food and chemical industries ${ }^{3}$.

In addition to its vast potential, chitosan has a low solubility. Chitosan was insoluble in neutral

This is an Open Access article licensed under a Creative Commons license: Attribution 4.0 International (CC- BY). Published by Oriental Scientific Publishing Company @ 2018

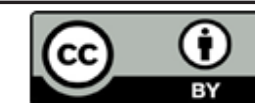


$\mathrm{pH}$, alkali and organic solvent solutions. This is of course limitting its application extensively ${ }^{4,5}$. The low solubility of chitosan is related to the degree of molecular weight. Low chitosan molecular weight has different conformation than other chitosan. In low molecular weight chitosan, there is a change of $\mathrm{N}$-acetylglucosamine unit content thus increasing solubility. In low molecular weight chitosan it is also associated with decreased intermolecular attraction such as Van der Waals force thus increasing its solubility in water ${ }^{6}$.

The depolymerization process will result in lower molecular weight and water soluble chitosan polymers well ${ }^{7}$. Water-soluble chitosan production is in great demand as it improves functional properties in its applications, such as increasing solubility and improving viscosity. Several methods were developed to produce water soluble chitosan through molecular weight reduction, ex. physical, chemical and enzymatic methods. Several studies have combined chemical and physical processes to produce chitosan ${ }^{8,9}$. Xie et al., ${ }^{10}$ performed enzymatic hydrolysis and was able to produce chitosan with lower molecular weight. However, enzymatic methods require high production costs. So much research refers to chemical chitosan hydrolysis. Several methods of chitosan hydrolysis are chemically developed with various acid catalysts. Phosphotungstic acid $\left(\mathrm{H}_{3} \mathrm{PW}_{12} \mathrm{O}_{40}\right)$ often used as a catalyst in the hydrolysis process. Phosphotungstic acid has many sides of bronsted acid that enhance its capability as hydrolysis agent, thereby may take a role on reducing the molecular weight. Its potential as hydrolysis catalyst due to its properties such as non-toxic, recyclable, low energy use, and minimal corrosion hazard ${ }^{11}$.

Steam explosion is a physicochemical method that uses high-pressure steam to break bonds between polymeric and decompression components to break down structures ${ }^{12}$. Chung et al., ${ }^{13}$ reported that can cleaving $\beta-\mathrm{O}-4$ linkages and $\mathrm{C} \alpha-\mathrm{C} \beta$ bonds on lignin during steam expolosion process. It will resulting in low molecular weight and good solubility of lignin. steam explosion process can resulting to lignin This method is widely used in the process of pretreatment in the process of hydrolysis, one of them in the production of chitosan. These steam explosions impair intermolecular interactions and produce free polymers ${ }^{14}$. The use of steam explosion in the deacetylation process or chitosan depolymerization is considered effective and environmentally friendly ${ }^{14}$.

In this research, chitosan hydrolysis will be done through pretreatment using steam explosion and phosphotungstic acid as a catalyst. It is expected that pretreatment using steam explosion process will break the hydrogen bond from chitosan, whereas Phosphotungstic acid catalyst will break the glycosidic bond of chitosan to obtain chitosan with low molecular weight and water soluble.

\section{MATERIALS AND METHODS}

\section{Materials}

Chitosan from shrimp shell waste by Sugiyanti et al., ${ }^{15}$ the catalysts phosphotungstic acid was purchased from Merck (Darmstadt, Germany), $\mathrm{CH}_{3} \mathrm{COOH}$ were purchased from Sigma Chemical Co. (St. Louis, MO, USA). All other reagents and chemicals were of analytical grade.

\section{METHODS}

Preparation of raw materials: Raw chitosan from shrimp shells was obtained from fresh shrimp products and processing plants located in Tambak Lorok, Semarang, Central Java, Indonesia according to Sugiyanti et al., ${ }^{15}$. The molecular weight (MW) and the degree of deacetylation were $55.7 \times 10^{4} \mathrm{Da}$ and $89.6 \%$, respectively.

Hydrolyzing chitosan using steam explosion under the catalysis of phosphotungstic acid: Chitosan sample was dissolved in $100 \mathrm{ml}$ aqueous acetic acid $1 \%(\mathrm{v} / \mathrm{v})$. The various concentration of phosphotungstic acid $(0,5 ; 0,75 ; 1 \mathrm{~g})^{16}$ were added into $1000 \mathrm{ml}$ of chitosan solution and then placed in the steam explosion reactor. Steam explosion experiments was according to Lorenzo-Hernando et al., ${ }^{17}$. It was conducted in a $1 \mathrm{~L}$ stainless-steel reactor, a steam generator was connected on top. The Reactor bottom discharge through an electro-valve to a flash vessel partially open to the atmosphere. The reactor was tightly closed and filled with saturated steam at the various temperature and pressure $\left(T=110^{\circ} \mathrm{C}, \mathrm{P}=1\right.$ bar; $\mathrm{T}=120^{\circ} \mathrm{C}, \mathrm{P}=2$ bar; $\mathrm{T}=130^{\circ} \mathrm{C}, \mathrm{P}=3$ bar; $\mathrm{T}=140^{\circ} \mathrm{C}, \mathrm{P}=4$ bar; $\mathrm{T}=150^{\circ} \mathrm{C}$, $P=5$ bar; $T=160^{\circ} \mathrm{C}, P=6$ bar; $T=170^{\circ} \mathrm{C}, P=7$ bar; and $\left.\mathrm{T}=180^{\circ} \mathrm{C}, \mathrm{P}=8 \mathrm{bar}\right)^{16,17}$. Thereafter, the mixture 
was homogenized with ultra turrax (Ika® Ultra-

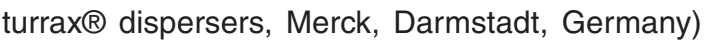
with rotation speed about $11.000 \mathrm{rpm}$ and dried by spray dryer (Labplant SD Basic Laboratory, UK) in inlet temperature of $120^{\circ} \mathrm{C}$ dan exhaust temperature $22^{\circ} \mathrm{C}$. The solubility of sample (\%) was calculated according to Alfaro et al., ${ }^{6}$ with some modification. $0.5 \mathrm{~g}$ sample was weight and placed in a beaker glass and distilled water was added until $50 \mathrm{ml}$. It was stirred (IKA RTC Basic, Wilmington, USA) for an hour and filtered by Whatman Filter Paper. The residu and filter paper were dried in an oven (Memmert, Germany) $105^{\circ} \mathrm{C}$ until constant weight. The initial sample weight was diminished with the constant weight of solid and filter paper then divided by the initial sample and multiplied by 100 to calculate the solubility (\%). The highest solubility was obtained to analyze using FTIR spectra, degree of crystallinity, molecular weight, particle size and SEM compared to chitosan originally.

\section{FTIR spectra}

Infrared Spectroscopy (FTIR) analysis of chitosan samples were carried out by FTIR spectrometer (Nicolet iS10 FTIR spectrometer, Thermo Scientific, USA) over a wavenumber range of $4000-400 \mathrm{~cm}^{-1}$. Smart iTR was used to collect horizontal attenuated total reflectance (ATR) spectra using. A Minigrip device was pressed to the samples to assure the uniform contact between samples and the ATR crystal. FTIR spectra were collected from at least 64 scans, using the OMNIC software (Thermo Scientific $)^{18}$.

Powder X-ray diffraction (XRD): X-ray diffraction data of chitosan were collected by X-ray diffractometer (D8, Advance Bruker XRD diffractometer, Germany) due to Hajji et al., ${ }^{19}$. The samples were put in porcelain cup and dried in an oven for $1 \mathrm{~h}$ at $100^{\circ} \mathrm{C}$. The dried samples were placed in a furnace at $1200^{\circ} \mathrm{C}$ for an hour. Thereafter, the samples were cooled at the room temperature and mashed with mortar. The crystallinity was then observed with the XRD pattern recorded using CuK $\alpha$ radiation $(\lambda=0.15406 \mathrm{~nm})$ at $40 \mathrm{kV}$ in the diffractometer. Scattering range $2 \theta$ of $5-40^{\circ}$ was recorded as the relative intensity. The error of this measurement was $\pm 1^{\circ}$. The calibration of XRD instruments was using standard reference materials (SRMs). XRD peak intensities on the basis of the constant total peak area and the various parameters were evaluated with a deconvolution procedure using Origin 6.0 (MicroCal Software Inc.).

\section{Average Molecular Weight}

The determination of average molecular weight (Mv) was due to Chouljenko et al., ${ }^{20}$ method with slight modification using an Oswald viscometer at room temperature. Chitosan and LWCS $(1 \mathrm{~g})$ was dissolved in $0.1 \mathrm{M}$ acetic acid/0.1 $\mathrm{M}$ sodium acetate. Then the time flow was determined through viscometer capillary and the relative viscosity, was also determined specific viscosity, inherent viscosity, and reduced viscosity by the following equation :

Relative viscosity $\left(\eta_{\text {rel }}\right)=\frac{\text { (efflux time of solution) }}{\text { (efflux time of solvent) }}$

Specific viscosity $\left(\eta_{\text {sp }}\right)=\eta_{\text {rel }}-1$

Inherent viscosity $\left(\eta_{\text {inh }}\right)=\left(\mid \ln \eta_{\text {rel }}\right) / c$

Reduced viscosity $\left(\eta_{\text {red }}\right)=\eta_{\text {sp }} / c$

Where c concentration of chitosan or LWCS in acetic acid/sodium acetate solution $(\mathrm{g} / \mathrm{dL})$

The viscosity of average molecular weight were estimated using Mark-Houwink equation:

$[\eta]=\mathrm{k}(\mathrm{Mv})^{\alpha}$

Where $[\eta]$ is the intrinsic viscosity and $k$ and $\eta$ are constants, chitosan $\mathrm{k}=0.078 \mathrm{~cm}^{3} \mathrm{~g}^{-1}$ and $\eta=0.76^{18}$.

\section{Particle size}

Chitosan particle WSC size were determined by scattering light intensity analysis using Horiba Laser Scattering Particle Size Distribution Analyzer LA-350 (Horiba Ltd., Kyoto, Japan), where the transmittance was $89.4 \%$, circulation speed 12 and automatic iteration mode. LWCS were determined by dynamic light scattering intensity analysis using Horiba Zetasizer Nano SZ-100 (Horiba Ltd., Kyoto, Japan), where the scattering angle $90,25^{\circ} \mathrm{C}$ of the holder temperature, dispersion medium viscosity $0.895 \mathrm{mPa} . \mathrm{s}$, transmission intensity before measure 28061, the polydisperse distribution form and the count rate was $1177 \mathrm{kCPS}$. The sample solution ( 0.5 $\mathrm{ml}$ ) in spectrophotometer cuvettes was analyzed and the Z-average particle size was reported as results. 


\section{Scanning electron microscopy (SEM)}

The morphology of the obtained chitosan and LWCS was examined under scanning electron microscopy (SEM) (Hitachi Ltd., Japan). An acceleration voltage $15 \mathrm{kV}$ and magnification range 50-10.000x was used.

\section{Statistical Analysis}

Each experiment was presented in triplicate. The data are reported as the mean \pm standard deviation (SD), analyzed by SPSS version 16.0 (SPSS Inc.). The significant of differences was determine by an analysis of variance (ANOVA) and Duncan's multiple range test $(p<0.05)$.

\section{RESULTS AND DISCUSSION}

\section{Solubility}

Steam explosion was used as a physicochemical method with high-pressure steam that disrupt polymeric bonding components and decompressed it to break the biomass structure ${ }^{21}$. Steam explosion used under thermomechanical force and high pressure that destroys the intermolecular interactions. The intermolecular interactions are broken by steam explosion which leads the formation of free polymer chains ${ }^{22}$. This physicochemical process producing LWCS can improve its solubility compared by chitosan originally (Figure 1).

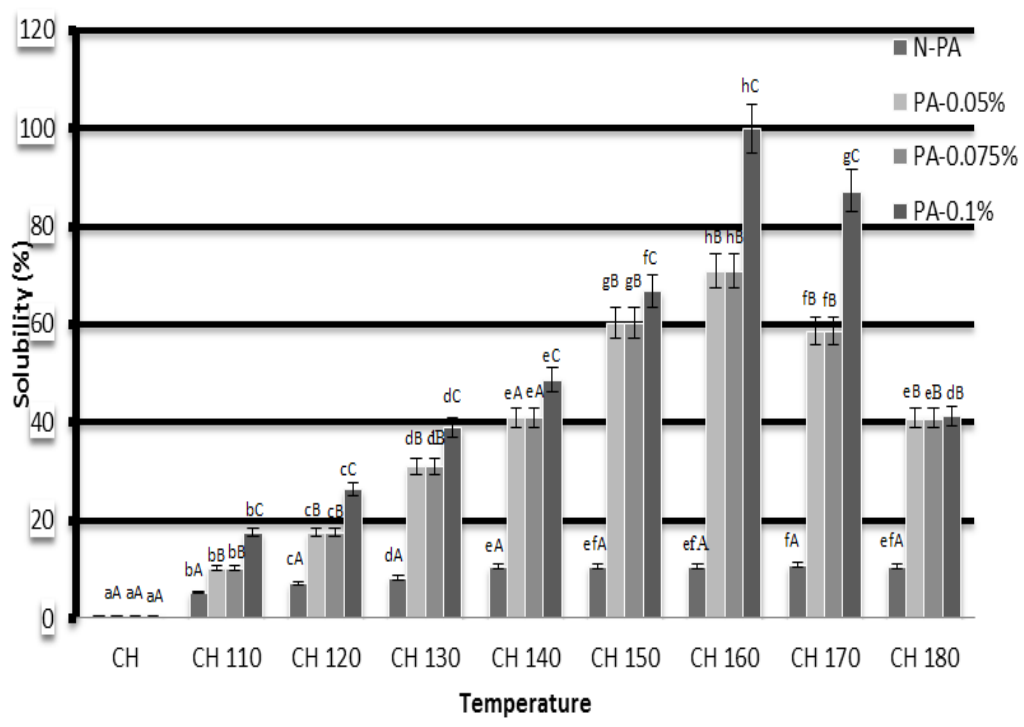

Fig. 1. The Percentage Solubility Chitosan by Steam Explosion Temperature and Phosphotungstic Acid Treatment

The results of this study indicate that the higher temperature on steam explosion process was resulting to increases the percentage solubility of chitosan. However, at temperatures of $170^{\circ} \mathrm{C}$ $\left(\mathrm{P}=7 \mathrm{bar}\right.$ ) and $180^{\circ} \mathrm{C}$ ( 8 bar) showed the decreasing solubility, it may be due to the temperature was too high, thus the optimal condition of pretreatment by using steam exsplosion is at $160^{\circ} \mathrm{C}$. While the influence of phosphotungstic acid catalyst concentration was equal with its solubility result. The high concentration of phosphotungstic acid was resulting to increase the water solubility. The most optimal concentration of phosphotungstic acid used was $0.1 \%$. Krishnan et al., ${ }^{23}$ was hydrolysing chitosan to LWCS by carbon based solid acid and results in LWCS with very good water-solubility at neutral $\mathrm{pH}$. Auxenfans et al., ${ }^{24}$ also studied that steam explosion
(SEP) process on lignocellulose sample shown the disorganize morphology structure. So that imply the disorganize structure can increased the solubility of cell component.

\section{FTIR analysis}

Fourier-transform infrared spectroscopy (FTIR) was used to obtain an infrared spectrum of samples that can identify the structure. The main bands in the spectrum of chitosan and LWCS were as follows: Both the $\mathrm{N}-\mathrm{H}$ stretching and $\mathrm{O}-\mathrm{H}$ stretching vibrations could be identified at $3287-3355 \mathrm{~cm}^{-1}$. The absorption peak at $2871 \mathrm{~cm}^{-1}$ corresponds to $\mathrm{C}-\mathrm{H}$ vibration of $\mathrm{CH}_{3}$ groups; the absorption peak at $1644 \mathrm{~cm}^{-1}$ indicates a carbonyl group; the absorption at $1586 \mathrm{~cm}^{-1}$ indicates $\mathrm{N}-\mathrm{H}$ bending vibrations of $\mathrm{R}-\mathrm{NH}^{2}$ groups; the absorption 
at $1375 \mathrm{~cm}^{-1}$ indicates amide groups; and the absorption both at 1026 and $1061 \mathrm{~cm}^{-1}$ indicates C-O stretching. LWCS produced by steam explosion method catalyzed with phosphotungstic acid doesn't show any structural damage, this demonstrated that the structures of the main chain of chitosan and LWCS have same functional group, obtained by FTIR spectra (Fig. 2). Huang et al., ${ }^{25}$ and Xia et al., ${ }^{16}$ also reported that hydrolysis using $\mathrm{H}_{2} \mathrm{O}_{2}$ didn't show any structural damage, discovered by the structures both chitosan and LWCS were the same.

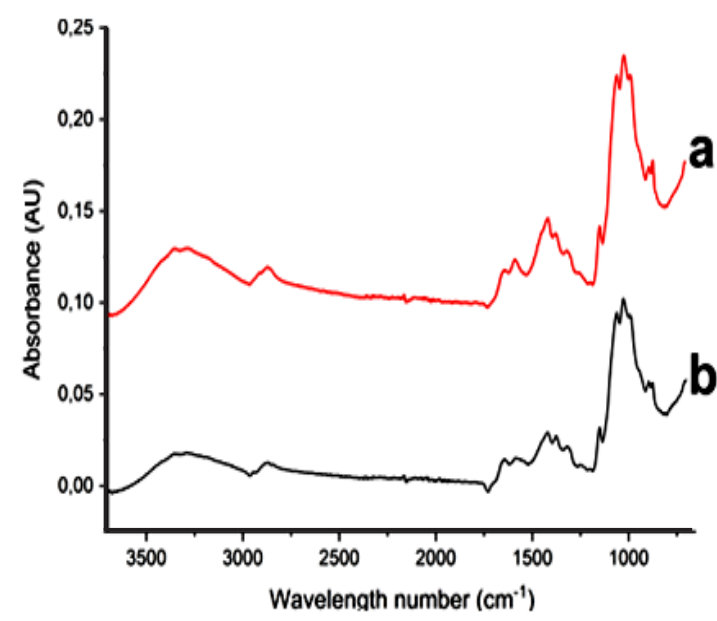

Fig. 2. FTIR spectra of (a) LWCS (water-soluble chitosan) and (b) Chitosan extracted from shrimp shell waste

\section{Crystallinity}

The crystallinity of chitosan and LWCS samples were characterized by X-ray diffraction (XRD). There was an alteration cristallinity of LWCS samples compared by chitosan originally (Fig. 3). The XRD pattern of chitosan show crystalline reflection at $9.49^{\circ}$ and $19.59^{\circ}$, while sharp peak at $10.1^{\circ}$ and $22.2^{\circ}$ on LWCS. The peak intensities were correlated with the degree of crystallization. These results have showed the decreases crystallization degree of LWCS, thus forms more amorphous structure than chitosan originally.

Besides the potential effect of steam explosion process, phosphotungstic acid used as a catalyst that completely decompose to $\mathrm{H}^{+}$and $\left[\mathrm{PW}_{12} \mathrm{O}_{40}\right]^{3-}$ in a aqueous solution. These protons will bond with the amine groups of chitosan molecules formed the electron-absent $\mathrm{R}-\mathrm{NH}^{3+}$, the repellency of protonated amine groups made chitosan stretched. Then it destroyed the structure and decreased the crystallinity of chitosan ${ }^{25}$. Krishnan et al., ${ }^{23}$ also reported that the LWCS production was decrease the crystalinity. Steam explosion on chitin sample indicates the deformation of the crystal structure. The exploded chitin samples showed the lower degree of crystallinity than raw chitin ${ }^{26}$.

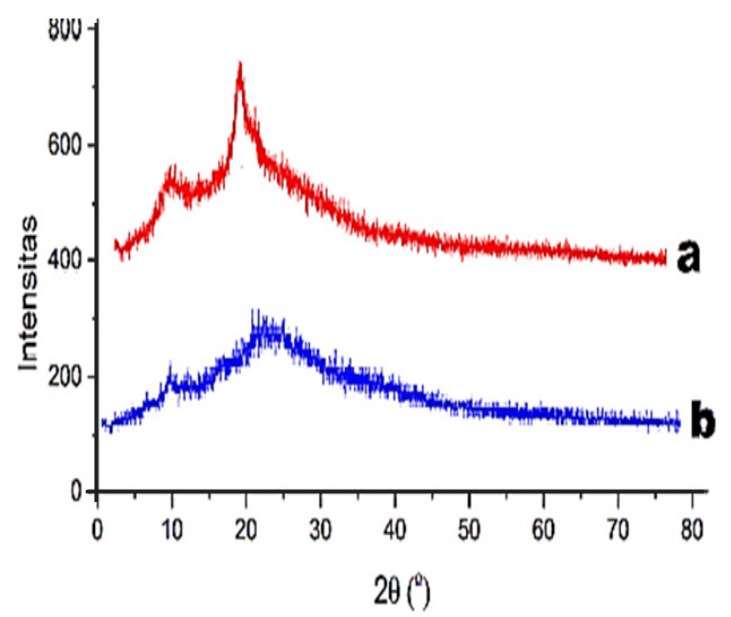

Fig. 3. X-ray diffraction patterns of (a) chitosan extracted from shrimp shells waste (b) chitosan extracted from shrimpshells waste after SEP

\section{Average Molecular Weight}

Average molecular weight analysis of chitosan and LWCS were carried out using Mark-Houwink equation and showed the decreasing average molecular weight of LWCS. LWCS have greatly lower molecular weight than chitosan. The reduction molecular weight was observed on LWCS sample that caused by the depolymerization of chitosan chains. In this study, there was a decrease molecular weight from $5570 \mathrm{kDa}$ to $480 \mathrm{Da}$. Chang et al., ${ }^{27}$, was studied that enzymatic hydrolysis of chitosan was effectively reduce its molecular weight from $300 \mathrm{kDa}$ to $156-2.2 \mathrm{kDa}$. In this research, LWCS processed using steam explosion process method. It was treated with saturated water steam in high temperatures and high pressures make the defibrillation of samples ${ }^{28}$. Pretreatment using steam explosion will break the hydrogen inter-molecular bond between chitosan so the acid hydrolysis will be easier to process. Chitosan hydrolysis catalized by phosphotungstic acid will break the $\beta$ - $(1,4)$ glycosidic bond. Phosphotungstic acid will decompose into $\left[\mathrm{H}^{+}\right]$ and $\left[\mathrm{PW}_{12} \mathrm{O}_{40}\right]^{3-}$ ions in solution, then these protons bind to amine groups of the chitosan molecules to form $\mathrm{R}-\mathrm{NH}^{3+}$. The presence of protonation in amine group made chitosan stretched which it decreases the crystallinity. then the ion $\mathrm{H}^{+}$will attact the $\mathrm{C}-1$ or 
C-4 carbon and causes the breaking of the glycoside bond and degraded to produce shorter chains ${ }^{25}$. The studied by Huang et al., ${ }^{26}$ using $\mathrm{H}_{2} \mathrm{O}_{2}$ and

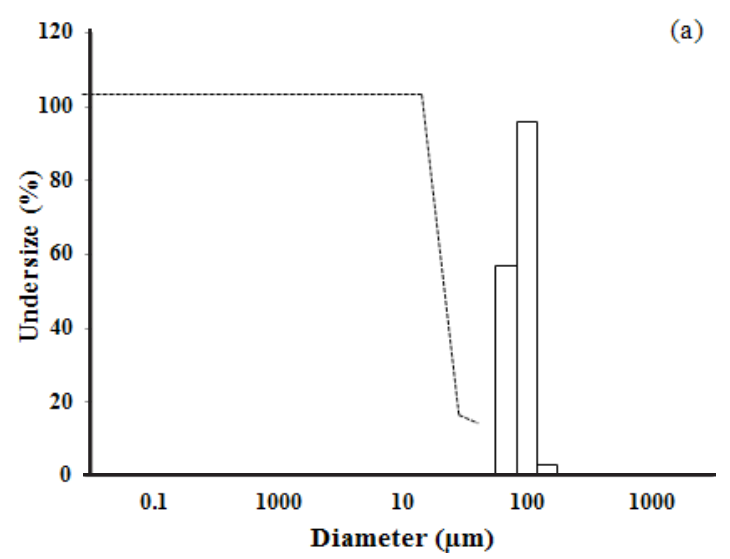

phosphotungstic acid was successfully degraded chitosan and reduced its molecular weight from 700.000 Da to 4.300 Da during 120 minutes.

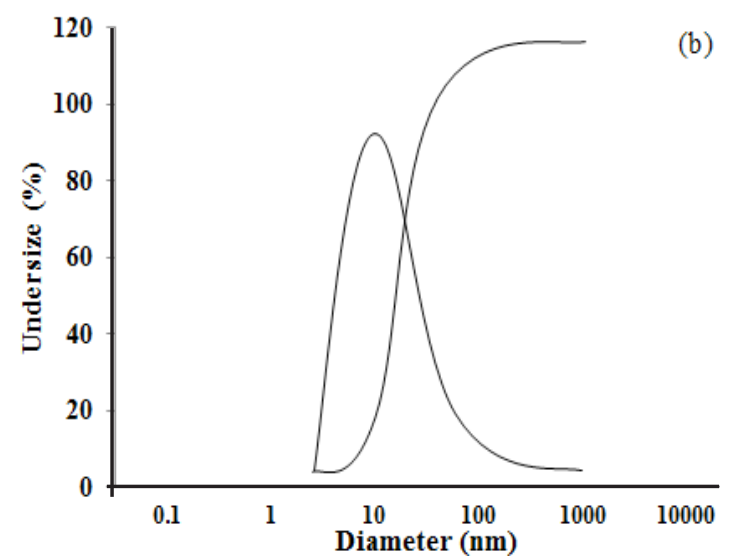

Fig. 4. Particle size of (a)chitosan extracted from shrimp shell waste and (b) LWCS extracted from shrimp shell waste

\section{Particle size}

Particle size determination was done by Scattering light intensity analysis method using Horiba Laser Scattering Particle Size (for chitosan) and Horiba Zetasizer Nano SZ-100 (for LWCS). The result shows that there was a reduction of particle size from $100 \mu \mathrm{m}$ to $255 \mathrm{~nm}$. The process of LWCS production was through homogenizing steps by ultra Turrax model. This model was widely used for emulsions preparation because it was simple to operate and can produce a good dispersing effect ${ }^{28}$. Peng et al., ${ }^{28}$ also observe that homogenation can decreasing the mean droplet diamater of particle size from $2373 \mathrm{~nm}$ to $168.7 \mathrm{~nm}$. These results indicate that homogenization have efficient effect on forming small droplet size in emulsions, the droplet was disrupted in rotor-stator system. Moreover, LWCS was processed by hydrolysis of the chitosan chain, so that terminates the polymer bonding and results in decreasing particle size. It was observed by Chouljenko et al., ${ }^{20}$, the chitosan hydrolysis using chitonase enzymes from Streptomyces sp. N174 also showed the reduction of chitosan particle size from 5066 to $757 \mathrm{~nm}$.

\section{Scanning electron microscopy (SEM) analysis}

The morphology of chitosan and LWCS samples were obtained by SEM. SEM was globally used to identify the morphological structures of samples or its derivative. SEM results of the chitosan and LWCS samples were presented in Fig. 5 with several magnifications, it showed the fibrous network forms a porous structure. LWCS samples presented more disorganize morphology characterized by the separation and loosening the fibrous network, so it has smooth surface. These results do not present the morphology damage. Thereby, it shows that the high temperature and high pressure technology on steam explosion process didn't caused structural damage on LWCS. Tan et al., ${ }^{30}$ also used steam explosion on chitin samples and shown the microfibril structures was disappeared and exhibited a smooth surface.

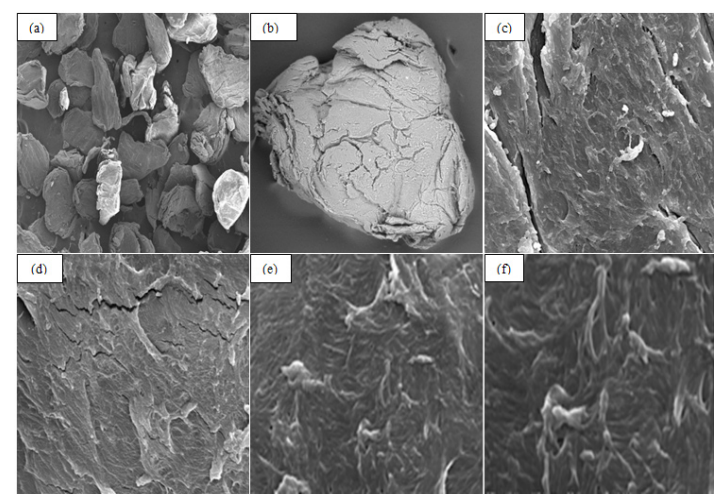

Fig. 5. SEM photographs of (a) LWCS extracted from shrimp shell waste magnifications at 50x, (b) LWCS extracted from shrimp shell waste magnifications at 310x, (c) LWCS extracted from shrimp shell waste magnifications at 1.000x, (d) LWCS extracted from shrimp shell waste magnifications at $10.000 x$, (e) Chitosan extracted from shrimp shell waste magnifications at 5000x and (f) Chitosan extracted from shrimp shell waste magnifications at $10.000 \mathrm{x}$

\section{CONCLUSION}

LWCS was produced by physicochemical 
hydrolysis through steam explosion process catalyzed by phosphotungstic acid with several design processes on temperature, pressure and phosphotungstic acid concentration. LWCS potentially has high solubility and fine characteristics. The results showed that LWCS have the same main structure with the chitosan originally estimated by FTIR methods. The XRD patterns confirm that the crystallinity of LWCS was lower than chitosan. It also has lower particle size and average molecular weight due to depolymerization process through steam explosion and acid hydrolysis. Both chitosan and LWCS have porous-fibril structures. LWCS shown no damage on morphological structures as well as chitosan.

\section{ACKNOWLEDGEMENT}

The authors gratefully acknowledge to the Directorate General of Islamic Higher Education, Ministry of Religion, Republic of Indonesia for supporting the Doctoral Program and Directorate General of Research and Development Strengthening, Ministry of Research, Technology and Higher Education of the Republic of Indonesia for financially supporting this research.

\section{REFERENCES}

1. Xia, W., Liu, P., Zhang, J., and Chen, J. Food Hydrocoll., 2011, 25, 170-179.

2. Olivera, S., Muralidhara, H. B., Venkatesh, K., Guna, V. K., Gopalakrishna, K., \& Kumar K., Y. Carbohydr Polym., 2016, 153, 600-618.

3. Muxika, A., Etxabide, A., Uranga, J., Guerrero, P., \& Caba, K. Int J Biol Macromol., 2017, 105, 1358-1368.

4. Wang, T., Turhan, M., and Gunasekaran, S. Polym Int., 2004, 53, 911-918.

5. Fu, Y., and Xiao, C. Int J Biol Macromol., 2017, 103, 575-580.

6. Alfaro, L., Chotiko, A., Chouljenko, A., Janes, M., King, J. M., \& Sathivel, S. Food Control., 2018, 85, 453-458.

7. Mourya, V.K. and Inamdar, N.N. React Funct Polym., 2008, 68, 1013-1051.

8. He, X., Li, K., Xing, R., Liu, S. and Hu, L. Egypt J Aqua Res., 2016, 42, 75-81.

9. Samar, M.M., El-Kalyoubi, M.H., Khalaf, M.M.and El-Razik, M.M.A. Ann Agric Sci., 2013, 58(1), 33-41.

10. Xie, H., Jia, X., Huang, J. and Zhang, C. Int J Chem., 2011, 3(2), 180-186.

11. Lu, Q., Cai, Z., Lin, F., Tang, L., Wang, S., and Huang, B. ACS Sustain Chem Eng., 2016, 4 (4), 2165-2172.

12. Li, J., Henriksson, G., and Gellerstedt, G. Bioresour Technol., 2007, 98, 3061-3068.

13. Chung, H. and Washburn, N.R. Lignin Polym Comp., 2016, 101, 13-25.

14. Sivashankari, P.R. and Prabaharan, M. Chitosan Based Biomat., 2017, 1, 117-133.

15. Sugiyanti, D., Darmadji, M., Anggrahini, S., Anwar, C., and Santoso, U. Pak J Nutr., 2018,
DOI: 10.3923/pjn.2018.

16. Xia, Z., Wu, S., \& Chen, J. Int J Biol Macromol., 2013, 59, 242-245.

17. Lorenzo-Hernando A., Martin-Juarez J. and Bolado-Rodriguez S. Carbohydr Polym., 2018, 191, 234-241.

18. Benhabiles, M. S., Salah, R., Lounici, H., Drouiche, N., Goosen, M.F.A., and Mameri, N. Food Hydrocoll., 2012, 29, 48-56.

19. Hajji, S., Younes, I., Ghorbel-Bellaaj, O., Hajji,R., Rinaudo, M., Nasri, M., and Jellouli, K. J. Int J Biol Macromol., 2014, 65, 298-306.

20. Chouljenko, A., Chotiko, A., Reyes, V., Alfaro, L., Liu, C., Dzandu, B. and Sathivel, S. Food Sci Technol., 2016, 74, 571-579.

21. Shrotri, A., Kobayashi, H. and Fukuoka, A. Adv Catal., 2017, 60, 59-123.

22. Jennings, A. and Bumgardner, J.D. United States : Woodhead Publ., 2015, 1.

23. Krishnan RA., Deshmukh P., Agarwal S., Purohit P., Dhoble D., Waske P., Khandekar D., Jain R. and Dandekar P. Carbohydr Polym., 2016, 151, 417-425.

24. Auxenfans, T., Cronier, D., Chabbert, B., and Paes, G. Biotechnol Biofuels., 2017, 10, 36.

25. Hsu, S.C., Don, T.M. and Chiu, W.Y. J Appl Polym Sci., 2002, 86, 3047-3056.

26. Huang, Q.Z. Carbohydr Polym., 2007, 68, 761-765.

27. Chang, S. Wu, C. and Tsai, G. Carbohydr Polym., 2018, 181, 1026-1032.

28. Thakur, V.K. Canada : Scrivener Publ., 2015.

29. Peng, J., Dong, W., Li, L., Xu, J., Jin, D., Xia, X. and Liu, Y. J. Food Drug Anal., 2015, 23, 828-835.

30. Tan, T.S., Chin, H.Y., Tsai, M. and Liu, C. Carbohydr Polym., 2015, 122, 321-328. 